\title{
INTERNATIONAL SPACE WEATHER INITIATIVE (ISWI)
}

\author{
Joseph M. Davila, Nat Gopalswamy, and Barbara Thompson
}

NASA-Goddard Space Flight Center

The International Heliophysical Year (IHY), an international program of scientific collaboration to understand the external drivers of planetary environments, has come to an end. The IHY was a major international event of great interest to the member States, which involved the deployment of new instrumentation, new observations from the ground and in space, and an education component. We propose to continue the highly successful collaboration between the heliophysics science community and the United Nations Basic Space Science (UNBSS) program.

One of the major thrust of the IHY was to deploy arrays of small instruments such as magnetometers, radio antennas, GPS receivers, all-sky cameras, particle detectors, etc. around the world to provide global measurements of heliospheric phenomena. The United Nations Basic Space Science Initiative (UNBSSI) played a major role in this effort. Scientific teams were organized through UNBSS, which consisted of a lead scientist who provided the instruments or fabrication plans for instruments in the array. As a result of the this program, scientists from UNBSS member states now participate in the instrument operation, data collection, analysis, and publication of scientific results, working at the forefront of science research. As part of this project, support for local scientists, facilities and data acquisition is provided by the host nation. In addition, support at the Government level is provided for local scientists to participate.

Building on momentum of the IHY, we propose to continue the highly successful collaboration with the UNBSS program to continue the study of universal processes in the solar system that affect the interplanetary and terrestrial environments, and to continue to coordinate the deployment and operation of new and existing instrument arrays aimed at understanding the impacts of Space Weather on Earth and the near-Earth environment. Toward this end, we propose a new program, the International Space Weather Initiative (ISWI). 


\section{The International Space Weather Initiative (ISWI)}

Joseph M. Davila, Goddard Space Flight Center, Greenbelt, MD, 20771 USA, email: Joseph.M.Davila@nasa.gov

\section{Abstract}

The International Heliophysical Year (IHY) provided a successful model for the deployment of arrays of small scientific instruments in new and scientifically interesting geographic locations, and outreach. The new International space Weather Initiative (ISWI) is designed to build on this momentum to promote the observation, understanding, and prediction space weather phenomena, and to communicate the scientific results to the public.

\section{Introduction}

The International Heliophysical Year (IHY) was an international program of scientific collaboration involving thousands of scientists from more than 70 countries, which was conducted from February 2007 to February 2009. Along with programs of research, outreach, and IGY history preservation, activities included the deployment of new instrumentation arrays especially in developing countries. A detailed account of all IHY activities is reported in the book The International Heliophysical Year: Putting the "I" in IHY, by Barbara J. Thompson, et al (2009).

It was recognized early in the planning of the IHY that the understanding of the global ionosphere and its linkage to the near-Earth space environment was limited by the lack of observations in key geographical areas, e.g. near the magnetic dipole equator. To address this need, a series of workshops were held to facilitate collaborations between research scientists in scientifically interesting geographic locations, and researchers with the expertise to build scientific instrumentation. From these meetings scientific teams emerged. Each team consisted of a lead scientist who provided the instruments or fabrication plans for instruments in the array. Support for local scientists, facilities and data acquisition was provided by the host nation. All scientists participate in the analysis of the data from the instrument array. As a result of the this program, scientists from many countries now participate in the instrument operation, data collection, analysis, and publication of scientific results, working at the forefront of science research. 

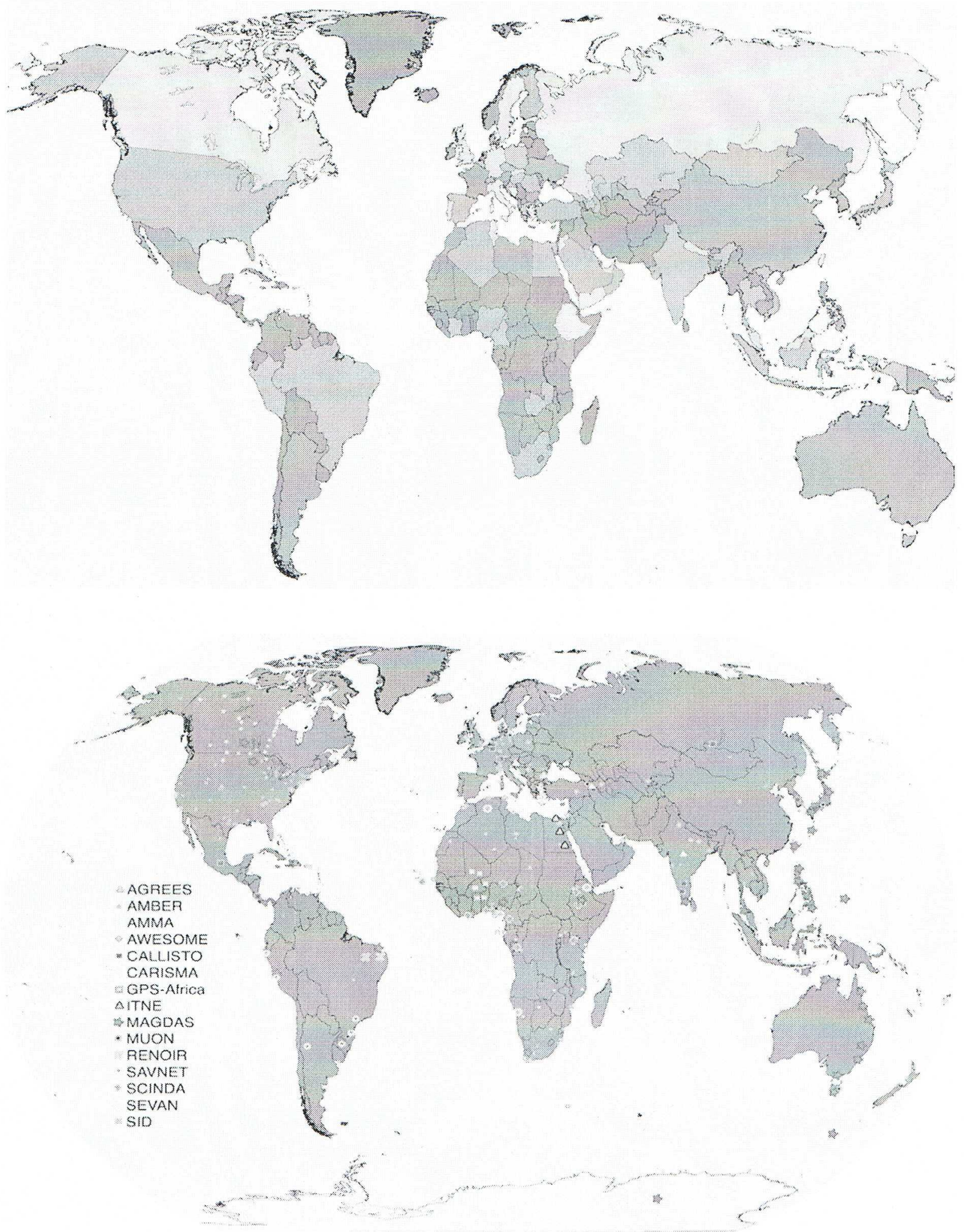

Figure 1 over 70 countres partipated in the HW whth national organing committeds, and almost 1000 instruments are currently cooperating in the program. 
The instrument deployment program was one of the major successes of the IHY. Arrays of small instruments such as magnetometers to measure Earth's magnetic field, radio antennas to observe solar coronal mass ejections, GPS receivers, VLF radio receivers, and all-sky cameras to observe the ionosphere, and muon particle detectors to observe energetic particles were installed around the world. These arrays continue to provide global measurements of heliospheric phenomena.

An interesting side benefit of the instrument program was the seeding of heliophysics research groups in universities where there had been none before, and the strengthening of existing heliophysics research groups where new instruments were installed.

Building on this concept, in February 2009 the International space Weather Initiative (ISWI) was proposed to the Science and Technology Subcommittee (STSC) of the United Nations. The program will continue the study of universal processes in the solar system that affect the interplanetary and terrestrial environments, and to continue to coordinate the deployment and operation of new and existing instrument arrays aimed at understanding the impacts of Space Weather on Earth and the near-Earth environment. The ISWI was adopted by the committee for the Peaceful Uses of Outer Space (COPUOS) in June 2009, and approved the UN General Assembly in the Fall of 2009. In addition to the United Nations, ISWI is supported by the National Aeronautics and Space Administration (NASA), the European Space Agency (ESA), the Japan Aerospace Exploration Agency (JAXA), and the International Committee on Global Navigation Satellite systems (ICG). Additional information on the ISWI is available at http://iswi-secretariat.org.

In this paper, we describe the goals and objectives of the IsWI program as it is currently envisioned.

\section{Goals and Objectives}

The ISWI will help develop the scientific insight necessary to understand the physical relationships inherent in space weather, to reconstruct and forecast near-Earth space weather, and to communicate this knowledge to scientists and to the general public. This will be accomplished by (1) continuing to deploy new instrumentation, (2) developing data analysis processes, (3) developing predictive models using data from the instrument arrays, and (4) continuing to promote knowledge of heliophysics through education and public outreach.

\section{Instrument Array Development}

The ISWI will continue to expand and deploy new and existing instrument arrays following the successful model demonstrated during the IHY. The basic principles of this model are simple. Each instrument team is led by 


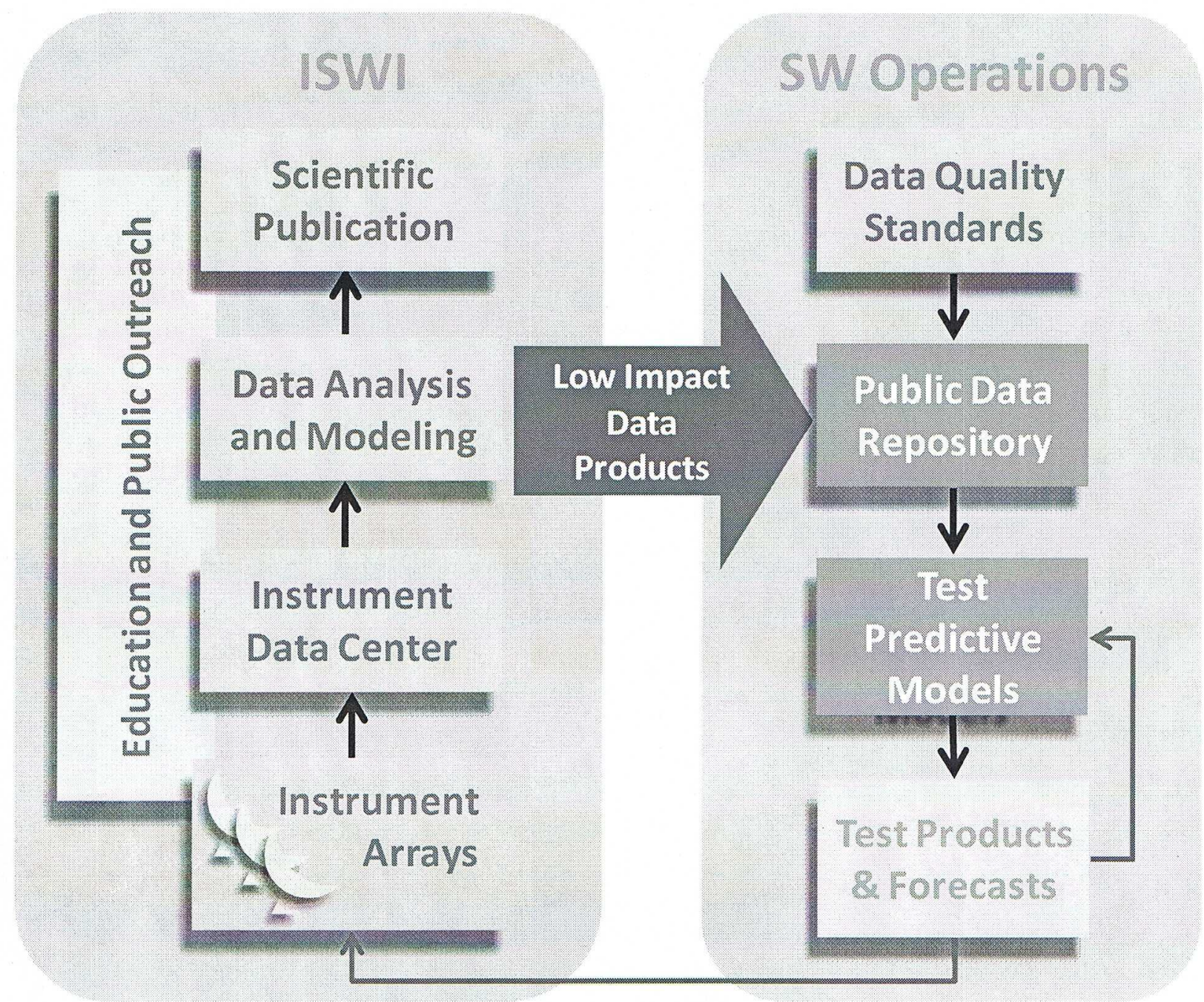

Figure 2 The instrments deployed in the ISW provide data usch lor Space Weather research and ron rorecasche.

a single scientist. The lead scientist or principle investigator, funded by his/her country, provides instrumentation (or fabrication plans) and data distribution. In a few cases, where resources allow, the hosting country will pay for the instrument. The host country provides the workforce, facilities, and operational support necessary to operate the instrument. This is typically at a local university or government laboratory. Host scientists become part of science team. All data and data analysis activity is shared within the science team, and all scientists participate in publications and scientific meetings where possible.

The current list of instrument providers is shown in Table 1. This list is not expected to remain static. Through workshops and other means, the ISWI will actively seek to identify additional instruments, and instrument providers that could benefit from the ISWI process, as well as new instrument hosts. 


\begin{tabular}{|c|c|c|c|c|}
\hline 1 & $\begin{array}{l}\text { Scintillation Network Decision } \\
\text { Aid } \\
\text { (SCINDA) }\end{array}$ & $\begin{array}{l}\text { K. Groves } \\
\text { keith.groves@hanscom.af.mil } \\
\text { (Hanscom AFRL) }\end{array}$ & USA & $\begin{array}{l}\text { Study equatorial ionospheric } \\
\text { disturbances to aid in the specification } \\
\text { and prediction of communications } \\
\text { degradation due to ionospheric } \\
\text { scintillation in the Earth's equatorial } \\
\text { region }\end{array}$ \\
\hline 2 & $\begin{array}{l}\text { lonospheric Tomography } \\
\text { Network of Egypt (ITNE) } \\
\text { Coherent lonospheric Doppler } \\
\text { Receiver (CIDR) }\end{array}$ & $\begin{array}{l}\text { A. Mahrous } \\
\text { amahrous@helwan.edu.eg } \\
\text { (Helwan University) } \\
\text { T. Garner } \\
\text { garner@arlut.utexas.edu } \\
\text { (University of Texas) }\end{array}$ & USA & $\begin{array}{l}\text { To tomographically reconstruct the } \\
\text { ionosphere and to provide input to data } \\
\text { assimilation models }\end{array}$ \\
\hline 3 & $\begin{array}{l}\text { Atmospheric Weather Education } \\
\text { System for Observation and } \\
\text { Modeling of Effects (AWE SOME) } \\
\text { and Sudden lonospheric } \\
\text { Disturbance monitor (SID) }\end{array}$ & $\begin{array}{l}\text { U. Inan } \\
\text { inan@stanford.edu } \\
\text { M. Cohen } \\
\text { mohen@stanford.edu } \\
\text { D. Scherrer } \\
\text { deborah@solar2.stanford.edu } \\
\text { (Stanford University) }\end{array}$ & USA & $\begin{array}{l}\text { Lightning, sprites, elves, relation to } \\
\text { terrestrial gamma ray flashes, whistler } \\
\text { induced electron precipitation, conjugate } \\
\text { studies. Education and public outreach. }\end{array}$ \\
\hline 4 & $\begin{array}{l}\text { Remote Equatorial Nighttime } \\
\text { Observatory for lonospheric } \\
\text { Regions } \\
\text { (RENOR) }\end{array}$ & $\begin{array}{l}\text { J. Makela } \\
\text { imakela@illinois.edu } \\
\text { (University of lllinois) }\end{array}$ & USA & $\begin{array}{l}\text { Study the equatoriallow-latitude } \\
\text { ionosphere/thermosphere system, its } \\
\text { response to storms, and the irregularities } \\
\text { that can be present on a daily basis }\end{array}$ \\
\hline 5 & $\begin{array}{l}\text { African GPS Receivers for } \\
\text { Equatorial Electrodynamics } \\
\text { Studies } \\
\text { (AGREES) }\end{array}$ & $\begin{array}{l}\text { E. Yizengaw (Boston College) } \\
\text { ekassie@igpp.ucla.edu } \\
\text { M. Moldwin (University Mich) }\end{array}$ & USA & $\begin{array}{l}\text { Understand unique structures in } \\
\text { equatorial ionosphere, lowimid latitude } \\
\text { plasma production, effect of ionospheric } \\
\text { and plasmaspheric irregularities on } \\
\text { communications }\end{array}$ \\
\hline 6 & $\begin{array}{l}\text { African Meridian B.field } \\
\text { Education and Research } \\
\text { (AMBER) }\end{array}$ & $\begin{array}{l}\text { M. Moldwin (University Mich) } \\
\text { mmoldwinalapp.ucla.edu } \\
\text { E. Yizengaw (Boston College) }\end{array}$ & USA & $\begin{array}{l}\text { Understand low latitude electrodynamics, } \\
\text { ULF pulsations, effect of PC5 ULF on MeV } \\
\text { electron population in inner radiation } \\
\text { belts }\end{array}$ \\
\hline
\end{tabular}




\begin{tabular}{|c|c|c|c|c|}
\hline D & MSTRUMENT & LeadScientist & Countuy & Objective \\
\hline 7 & $\begin{array}{l}\text { Compound Astronomical } \\
\text { Low-cost Low-frequency } \\
\text { Instrument for } \\
\text { Spectroscopy and } \\
\text { Transportable Observatory } \\
\text { (CALLISTO) }\end{array}$ & $\begin{array}{l}\text { A.Benz } \\
\text { benz@astro.phys.ethz.ch } \\
\text { C. Monstein } \\
\text { monstein@astro.phys.ethz.ch } \\
\text { (ETH) }\end{array}$ & Switzerland & $\begin{array}{l}\text { Study of radio flares caused by solar activity } \\
\text { in view of space weather and climate change }\end{array}$ \\
\hline 8 & $\begin{array}{l}\text { South Atlantic Very Low } \\
\text { frequency Network } \\
\text { (SAVNET) }\end{array}$ & $\begin{array}{l}\text { J.P. Raulin } \\
\text { raulin@ocraam.mackenzie.br } \\
\text { (University Presbiteriana) }\end{array}$ & Brazil & $\begin{array}{l}\text { Study of the SAMA region at low } \\
\text { ionospheric altitudes and its structure } \\
\text { and dynamics during geomagnetic } \\
\text { perturbations }\end{array}$ \\
\hline 9 & $\begin{array}{l}\text { Magnetic Data Acquisition } \\
\text { System (MAGDAS) }\end{array}$ & $\begin{array}{l}\text { K. Yumoto } \\
\text { yumoto@serc.kyushu-11.ac.jp } \\
\text { (Kyushu University) }\end{array}$ & Japan & $\begin{array}{l}\text { Study of dynamics of geospace plasma } \\
\text { changes during magnetic storms and } \\
\text { auroral substorms, the electromagnetic } \\
\text { response of iono-magnetosphere to } \\
\text { various solar wind changes, and the } \\
\text { penetration and propagation } \\
\text { mechanisms of DP2.ULF range } \\
\text { disturbances }\end{array}$ \\
\hline 10 & $\begin{array}{l}\text { African Dual Frequency } \\
\text { GPS Network }\end{array}$ & $\begin{array}{l}\text { C. Amory-Mazaudier } \\
\text { christine.amory@lpp.polytechnique.fr } \\
\text { (CETP/CNRS) }\end{array}$ & France & $\begin{array}{l}\text { To increase the number of real-time dual- } \\
\text { frequency GPS stations worldwide for } \\
\text { the study of ionospheric variability, } \\
\text { response of the ionospheric total } \\
\text { electron content (TEC) during } \\
\text { geomagnetic stoms over the African } \\
\text { sector }\end{array}$ \\
\hline
\end{tabular}




\begin{tabular}{|c|c|c|c|c|}
\hline 1D & MSTFUMETT & LeadSctenist & Countsy & Objective \\
\hline 11 & $\begin{array}{l}\text { Space Environmental } \\
\text { Viewing and Analysis } \\
\text { Network } \\
\text { (SEVAN) }\end{array}$ & $\begin{array}{l}\text { A.Chillingarian } \\
\text { chiligaragats.am } \\
\text { (Aragats University) }\end{array}$ & Armenia & $\begin{array}{l}\text { A network of particle detectors that aims } \\
\text { to improve fundamental research of the } \\
\text { particle acceleration in the vicinity of the } \\
\text { Sun and the space environment, as well } \\
\text { as to provide forewarnings of dangerous } \\
\text { consequences of space stoms }\end{array}$ \\
\hline 12 & $\begin{array}{l}\text { Global Muon Detector } \\
\text { Network } \\
\text { (GMDN) }\end{array}$ & $\begin{array}{l}\text { K. Munakata } \\
\text { kmunaooashinshu.u.ac.jp } \\
\text { (Shinsu University) }\end{array}$ & Japan & $\begin{array}{l}\text { To identify the precursory decrease of } \\
\text { cosmic ray intensity that takes place } \\
\text { more than one day prior to the Earth- } \\
\text { arrival of shock driven by an } \\
\text { interplanetary coronal mass ejection }\end{array}$ \\
\hline 13 & $\begin{array}{l}\text { Flare Monitoring } \\
\text { Telescopes (FMT) under } \\
\text { the Continuous H-alpha } \\
\text { Imaging Newwork (CHAIN) }\end{array}$ & $\begin{array}{l}\text { S. UeNo } \\
\text { ueno@kwasan.kyoto-u.ac.ip } \\
\text { K. Shibata } \\
\text { (Kyoto University) }\end{array}$ & Japan & $\begin{array}{l}\text { Time variation and 3D velocity field of } \\
\text { solar activity, flares, filament eruptions } \\
\text { and shock waves (Moreton waves) by } \\
\text { using multi-wavelength H-alpha images } \\
\text { of the full-disk Sun. }\end{array}$ \\
\hline 14 & $\begin{array}{l}\text { Optical Mesosphere } \\
\text { Themosphere Imagers } \\
\text { (OMTIs) }\end{array}$ & $\begin{array}{l}\text { K. Shikawa } \\
\text { shiokawa@stelab.nagoya-u.acip } \\
\text { (Nagoya University) }\end{array}$ & Japan & $\begin{array}{l}\text { Dynamics of the upper atmosphere } \\
\text { through nocturnal airglow emissions } \\
\text { htp://stdb2. stelab.nagoya- } \\
\text { u.ac.jplomtilindex.html }\end{array}$ \\
\hline
\end{tabular}




\section{Data Analysis}

The ISWI program will promote the coordination of data products in a form useful for input into physical models of heliospheric processes. These data will be used for both retrospective analysis aimed at physical understanding of space weather, and for predictive models to predict future space weather conditions.

To be useful for space weather prediction, data must be available in near real-time. However, today internet connections are intermittent or slow in many locations in the developing world, making near real-time data return impossible. Eventually, as internet connectivity improves, these data will be made available in near real-time in a form where they can be ingested into predictive models. In the near term, other strategies like data transfer during selected time periods, or on recorded media like DVDs and tapes are adequate for the retrospective scientific studies of space weather events, and the development of physical models.

Data from the instrument arrays will be deposited in publicly available archives. For the most part, these will be existing data archives, like the virtual observatory systems which are currently under development, similar to the Virtual Heliospheric observatory (http://vho.nasa.gov/) or the Virtual solar observatory

(http://http://sdac.virtualsolar.org/cgi/search). This will make data from ISWI instruments available to the broader community of researchers.

\section{Training, Education, and Outreach}

During the IHY space science schools in US, China, India, Brazil, and Nigeria provided training to hundreds of graduate students and new researchers. The ISWI will continue to provide support for space science schools. The ISWI will continue to promote space science and the inclusion of space science curricula in universities and graduate schools. This has been most effective when combined with the installation of instrumentation at the university.

The ISWI will continue to support public outreach projects. It is essential to communicate the excitement, the beauty, and the relevance of our science to scientists from other disciplines, and to the public at large. We will continue to develop public outreach materials unique to the ISWI, and coordinate the distribution these materials through individual contacts and outreach workshops.

\section{Summary and Conclusions}

The ISWI will continue a portion of the IHY program, providing a forum for the formation of scientific collaborations between instrument providers and instrument hosts. Initially data will be used primarily for understanding the physical processes important for space weather phenomena. Later, ISWI will move toward near real-time data availability as internet connectivity improves, allowing data ingest predictive 
modeling. A robust program of outreach is envisioned, with a continuation of the space science schools, support for university space science curricula, and a public outreach program. 